\title{
Atraumatic Technique for Removal of Lingually Placed Mandibular Teeth
}

\author{
Arvind Karikal ${ }^{1, \odot}$ Tripthi P. Shetty ${ }^{1, \odot}$ Gopinath Thilak P.S. ${ }^{1} \quad$ Arathi Kudthadka $^{2}$ \\ ${ }^{1}$ Department of Oral and Maxillofacial Surgery, A.B. Shetty \\ Memorial Institute of Dental Sciences, Derlakatte, Mangalore, \\ Karnataka, India \\ 2Department of Oral Pathology, A.J. Institute of Dental Sciences, \\ Mangalore, Karnataka, India

\begin{abstract}
Address for correspondence Tripthi P. Shetty, MDS, Department of Oral and Maxillofacial Surgery, 6th Floor, A.B. Shetty Memorial Institute of Dental Sciences, Derlakatte, Mangalore 575018, Karnataka, India (e-mail: tripthisurgeon@gmail.com).
\end{abstract}

J Health Allied Sci ${ }^{\mathrm{NU}}$ 2021;11:193-195.
Abstract
Keywords
- atraumatic
- extraction
- novel technique

We describe an innovative and easy method to remove lingually placed mandibular single-rooted teeth which are not accessible to regular forceps method of extraction. This method is simple and atraumatic and preserves the lingual alveolar plate which is important for implant placement and socket perseveration. This note is aimed at highlighting a simple atraumatic technique for removal of these types of single-rooted teeth erupting on the lingual side with the help of surgical screws. This technique is more economical and considerably less cumbersome than the existing Benex system.

\section{Introduction}

With the trend in implants for rehabilitation of extracted teeth, the preservation of the alveolar plates and viable bone is of utmost importance. Extraction of malaligned/ unerupted/lingually placed teeth atraumatically is a complex challenge. Many techniques have been designed and modified overtime to preserve alveolar plate postextraction. Although these techniques may produce the desired results, they are highly technique-sensitive and skilled procedures requiring elaborate armamentarium and finesse.

The advent of our method, therefore, has been a result of efforts to overcome the shortcomings and hence design a simple and effective technique to remove precariously placed mandibular teeth. This note is aimed at highlighting a simple atraumatic technique for removal of these types of single-rooted teeth erupting on the lingual side with the help of surgical screws. The technique is a more economical and considerably less cumbersome than the existing Benex system.

Lingually placed mandibular teeth pose many a challenge for extraction. Decreased access to engage the extraction forceps onto the cervical area, unfavorable path of exit, fragile, and thinned-out cortical plates adjacent to the tooth to name a few. The technique mentioned here addresses these challenges in the simplest of ways. The procedure involves drilling and securing a surgical screw into the tooth to be extracted along its long axis, such that it can be retrieved along the vertical path with minimal trauma. This ensures adequate preservation of the associated hard and soft tissues.

\section{Methods}

The technique was employed on patients requiring routine extraction of malaligned/unerupted/lingually placed mandibular teeth reporting to the clinical section. The location and depth of the malposed tooth is confirmed with radiological imaging. Cone-beam computer tomograph is ideal, as it precisely determines the position and depth of

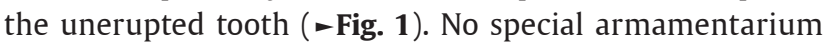
or equipment will be required. Existing surgical screws of 1.1 to $1.5 \mathrm{~mm}$ in diameter and 8-mm length, a drill bit of the similar diameter and a screw holder will be sufficient (-Fig. 2). After administration of local anesthesia, the mucoperiosteum is reflected and the crown of the tooth is completely exposed. The diameter of the drill bit and depth published online January 24, 2021
DOI https://doi.org/

10.1055/s-0040-1722799 ISSN 2582-4287.

\footnotetext{
(c) 2021. Nitte (Deemed to be University).

This is an open access article published by Thieme under the terms of the Creative Commons Attribution-NonDerivative-NonCommercial-License, permitting copying and reproduction so long as the original work is given appropriate credit. Contents may not be used for commercial purposes, or adapted, remixed, transformed or built upon. (https://creativecommons.org/licenses/by-nc-nd/4.0/).

Thieme Medical and Scientific Publishers Pvt. Ltd. A-12, 2nd Floor, Sector 2, Noida-201301 UP, India
} 


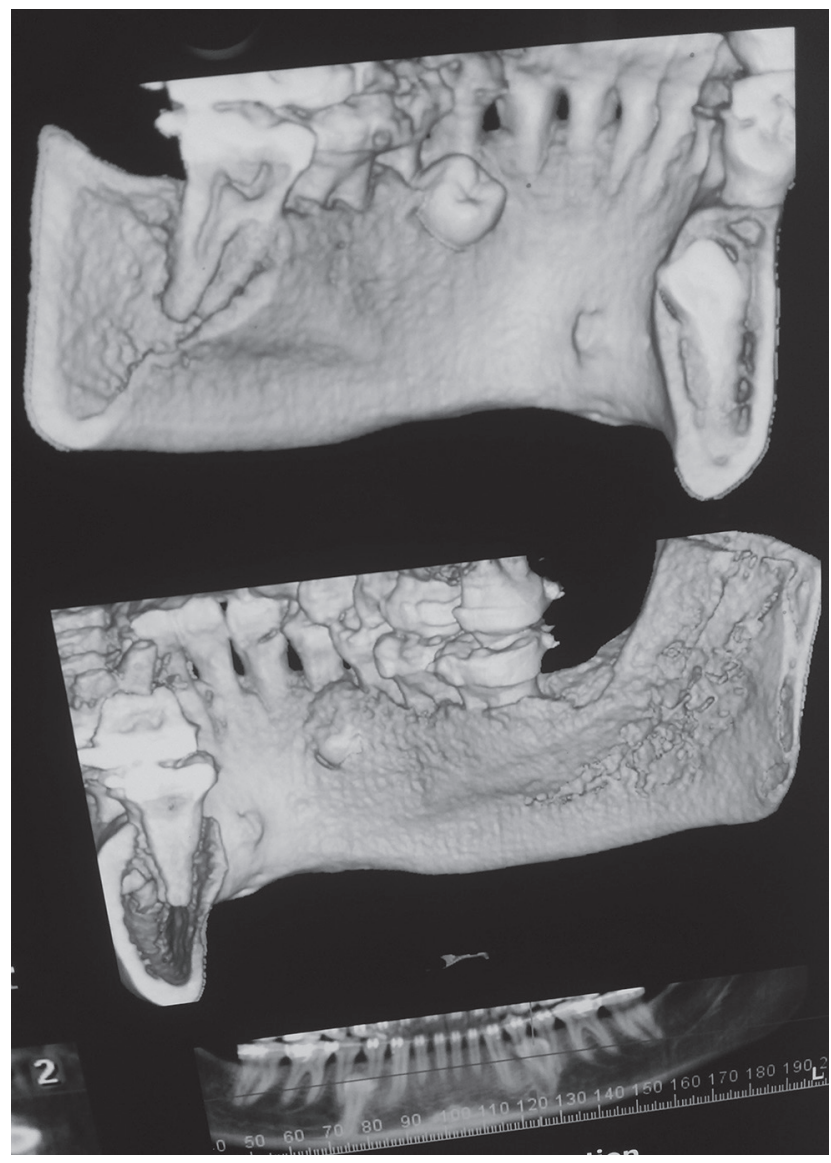

Fig. 1 The location and depth of the malposed tooth is confirmed with cone-beam computer tomography imaging.

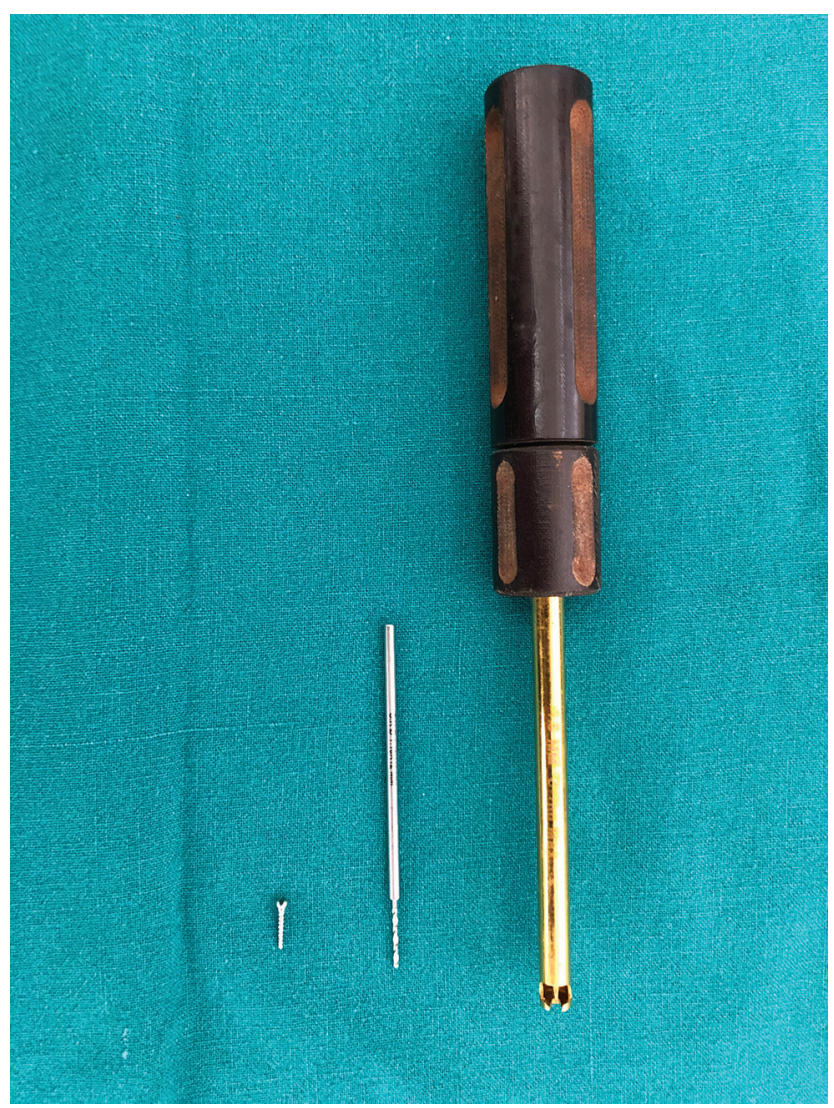

Fig. 2 Required instruments (armamentarium). of penetration of the drill into the tooth are determined by the size and length of the tooth accordingly. A surgical drill bit of $1.1-\mathrm{mm}$ diameter is ideal for most of the malposed single-rooted teeth. A depth of $6 \mathrm{~mm}$ into the tooth structure is the ideal penetration depth ( $\boldsymbol{- \text { Fig. }} \mathbf{3})$. The surgical bit is used to drill into the crown of the tooth to the determined depth and a surgical screw of $1.5 \mathrm{~mm} \times 8 \mathrm{~mm}$ is then secured in place. A surgical screw of $2 \mathrm{~mm}$ is left above the crown which enables adequate adaptation of the screw holder to the screw and hence a snug fitted onto the tooth ( - Fig. 4). Next optimum upward traction is applied along the long axis of the tooth with the screw holder and the tooth is dislodged from the socket ( $\mathbf{- \text { Fig. }} \mathbf{5}$ ).

This innovative technique of tooth removal was employed on selective patients coming to the outpatient department of our institute. Patients included in this technique had lingual erupting teeth and required their extraction for orthodontic treatment and implant placement. We successfully performed this method of extraction on eight patients during 3 months.

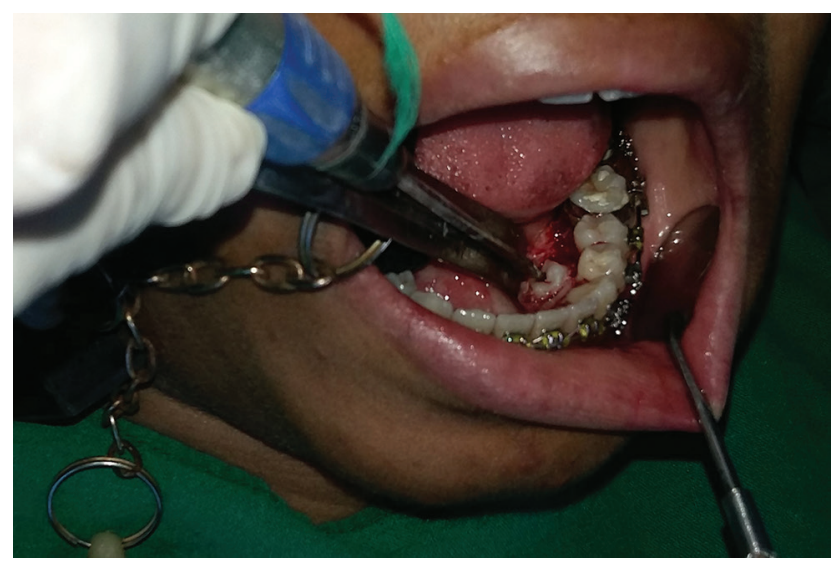

Fig. 3 Adaptation of the screw and screw holder.

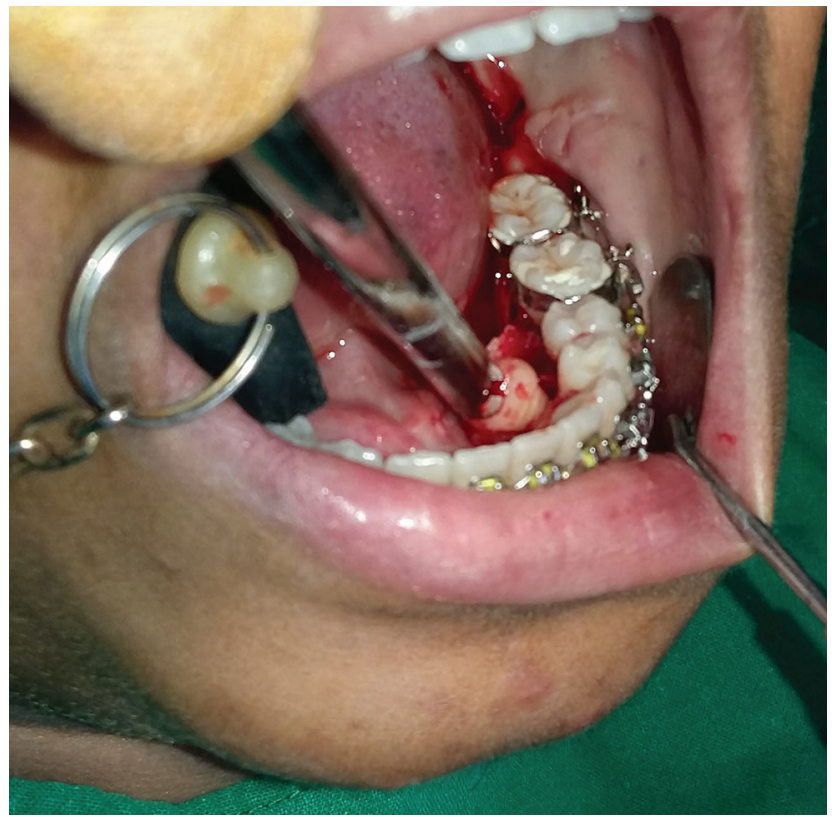

Fig. 4 Retrieval of extracted tooth. 


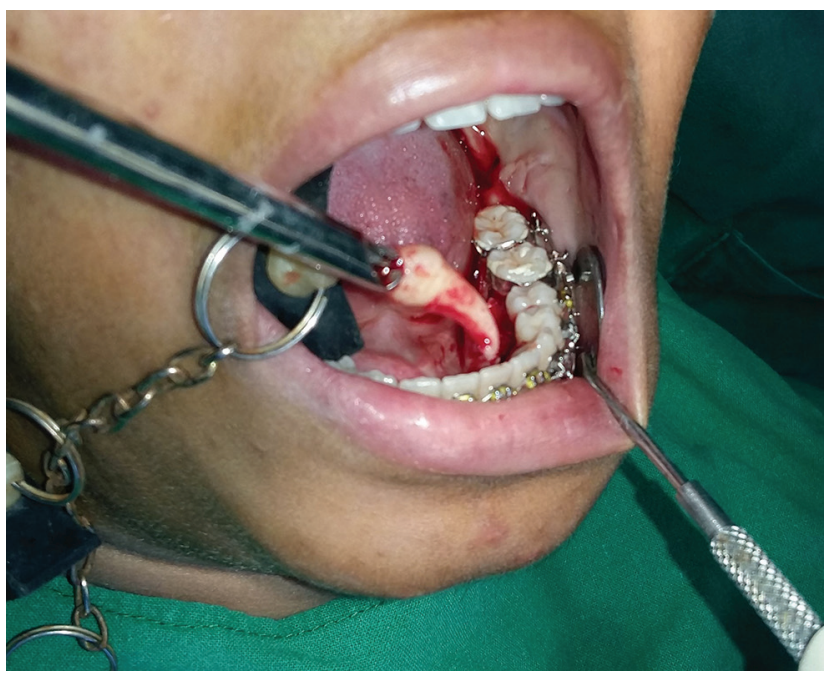

Fig. 5 Extracted tooth.

Written informed consent and oral explanation were given to each patient before the technique was employed. Ethical clearance from the institute was not applicable as this is not a study setting but a routine treatment to the patient.

\section{Results}

The technique was successfully used to extract a total of eight single-rooted premolars placed precariously in eight patients over a period of 3 months.

\section{Discussion}

This is an atraumatic and a relatively simple technique that does not require expensive equipment. It requires minimal reflection of the mucoperiosteum with excellent preservation of the alveolar plates. Vertical traction applied after engaging the screw ensures minimal trauma to the alveolar plates. It can be performed in situations where regular forceps is inaccessible. Its limitation, however, is that the technique that can be adopted only for single-rooted teeth without any morphological deviation. The Benex system, ${ }^{1}$ however, requires direct access to the tooth in question and the appliance is difficult to be applied, especially in lingually tilted or submerged teeth. Our novel innovative technique using surgical screws, however, is easily reproducible by the majority of oral surgeons and is a good alternative technique for atraumatic removal of lingually tilled or submerged teeth.

\section{Note}

Written informed consent of the patient has been taken.

\section{Conflict of Interest}

None declared.

\section{Reference}

1 Muska E, Walter C, Knight A, et al. Atraumatic vertical tooth extraction: a proof of principle clinical study of a novel system. Oral Surg Oral Med Oral Pathol Oral Radiol 2013;116(5):e303-e310 